\title{
Research on the Reform of the Preliminary Course of Architectural Design Based on Innovation \& Practice Ability Training
}

\author{
Cai Yuping ${ }^{1} \&$ Liang Shuang ${ }^{1}$ \\ ${ }^{1}$ School of Civil Engineering and Architecture, Southwest University of Science and Technology, Mianyang, \\ China \\ Correspondence: Cai Yuping, No. 59, Qinglong Road, Fucheng District, School of Civil Engineering and \\ Architecture, Southwest University of Science and Technology, Mianyang, China. Tel: 86-158-8162-6119. \\ E-mail: 24439854@qq.com
}

Received: February 13, 2017

Accepted: March 21, $2017 \quad$ Online Published: June 27, 2017

doi:10.5539/ies.v10n7p103

URL: https://doi.org/10.5539/ies.v10n7p103

\begin{abstract}
The traditional undergraduate education mode of architecture has been unable to adapt to the rapid development of society. Taking the junior professional course of architecture - the preliminary course of architectural design as an example, this paper analyzes the problems existing in the current professional courses of lower grades, puts forward the opinion that the cultivation of innovation \& practice ability should be included in the professional training objectives, and the corresponding reforms of the training program and teaching methods should be made, in order to provide the reference for the construction in the basic teaching of architecture.
\end{abstract}

Keywords: innovation ability, practice ability, training objectives, training program, teaching methods

\section{Introduction}

In order to cope with the increasingly complex problems of urban and architectural development, profound changes have taken place in the connotation and extension of Architecture: on the one hand, architectural education will pay more attention to the understanding and application of other related disciplines, especially the humanities, so as to form a generalized teaching system which is more closely integrated with the social reality, profession and general education; on the other hand, architectural education as a kind of professional education without a "uniformly standard answer" will be more embodied in the process of exploratory teaching, which is to find, analyze and solve problems, and the students' ability to deal with complex problems and their comprehensive quality will be improved through this process. Therefore, reforming teaching system and strengthening practice is not only an urgent need for the development of architectural education, but also an inevitable trend of cultivating innovative talents.

The preliminary course of architectural design is the most important professional course for architectural undergraduates in the lower grades. It's the preparative and initial stage of a series of courses in building design. The teaching content mainly includes basic professional theory, cognition, skills and architectural design method, etc. In the past decades, we have always paid more attention to the foundation of professional knowledge and skills for the further study, but ignored the training of the practice and innovation ability in engineering. As a result, practice curricula in the higher grades cannot be connected well with preliminary curricula, students are not active in the design process and their ability to solve social problems is poor.

\section{The Revision of Training Objectives}

The previous teaching objective of preliminary course of architectural design is to cultivate students with the structure of professional basic knowledge, basic skills and design thinking. It focuses on the teaching of basic theories. The students may have a solid theory foundation, but they're not good at finding problems, analyzing problems and solving problems.

The Ministry of Education mentioned that "facing the industry, the world and the future, a large number of various high-quality engineers with strong innovation ability should be cultivated to meet the needs of economic and social development" in the education program of outstanding engineers. Our college wants to implement the program as a breakthrough, promoting the reform and innovation of engineering education. So we revise the training objectives of the junior design courses in architecture to place great emphasis on the cultivation of 
practice and innovation ability. The practice segment has been added into the professional basic teaching, and the frontier theory has been consciously infiltrated into the subject. Understanding the major through theory study, acquiring skills through operation and practice, thinking deeply through extended research, students can have the consciousness of engineering practice and the sensitivity of the subject frontier while learning professional theory at the beginning of school. It is laying the foundation for training innovative design thinking.

\section{The Reform of Training Program}

According to the training objectives, we have to adjust training program and curriculum framework. We combined engineering quality training and frontier theory guiding with basic teaching to achieve the integration of teaching links. Taking basic teaching as the core, design thinking ability has been cultivated; Taking frontier theory and engineering quality as the assistant, the innovation and practice ability for design have been strengthened; these constitute our curriculum framework (i.e., Figure 1). When revising the training program, we should take notice that it needs relative adjustment space to the variety of society and talents, or else it will destroy the cultivation system, structure and method, and also affect its operability.

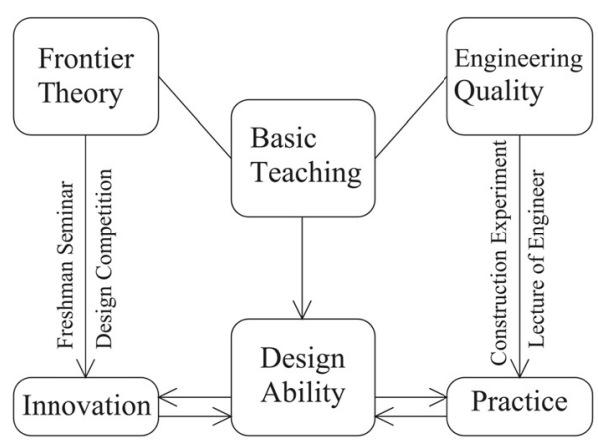

Figure 1. Curriculum framework

\subsection{Revising the Topics and Tasks of Curriculum Design}

In the past, the curriculum design topics of lower grades we used are mostly virtual. That is, the teachers ask the students do the design on the fictitious sites with a few restrictions of surrounding environment conditions. Now we introduce the real living environment, including campus, dormitory and community which need partial transformation, etc. Otherwise, we obtain the sub project topics from actual projects. In the early design stage, students need to do a lot of social investigation and site survey, which can mobilize their initiative to focus on the social practical problems. The topics are no longer only related to the new building types, since China's construction has entered into the stock age from the increment age. Reconstruction projects will involve more problems, for instance, the physiological and psychological needs of the user, behavior habits, emotional factors, structural reinforcement, energy-saving reconstruction, etc. Students should adapt to the social transformation as soon as possible, for becoming an excellent architect in the future.

\subsection{Strengthening the Cultivation of Practice Ability in "Teaching” And "Learning"}

We hold construction festival every year. Students could use different types of materials to build with 1:1 proportion according to specific function and space requirements after being grouped. The whole process of building planning, designing, construction, using and demolition can be understood and experienced by students through the construction festival. It cultivates the original design ability from function $\&$ material and the executive power to implement the design, gives students the opportunity to experience the true construction process and be familiar with the performance of connected nodes with various materials, trains the team cooperation ability and social activity ability of architect. In addition, we invite the experienced engineers in institutes of architectural design into our classroom. They give students lectures and participate in the public commentary of drawings, sharpen their understanding of actual problems and design specifications, which could improve students' comprehensive engineering quality.

The assignments of space cognition and mapping for small buildings are added to the course after class. Space cognition is divided into three stages: spatial perception, spatial recognition and spatial symbolization. At first, students enter the different types of substantial space and observe the characteristics of various single spaces and 
combinatorial spaces. Then the relationship between "part-whole" and "function-form" could be concluded and deduced by students. Finally, they complete the investigation report with amusing symbolic language. Small building surveying and mapping is mainly in order to develop the sense of scale and standardize in students and the expression of engineering drawings.

\subsection{Carrying Out the Freshman Seminars and All Kinds of Design Competitions}

At the beginning of the preliminary course of architectural design, we carry out the freshman seminar and introduce the frontiers of subject, guiding students to think the profession, making them concern over social hot issues and training their creative thinking. The intramural design competition and model competition are held every year, and students are encouraged to participate in various international and national design competitions. The topics of these competitions are not alone in fields closely related to the hot issue of the subject, for example, e+ (something plus internet), maker space 2.0, transformation for aging, etc. Many other multi-disciplinary integrated topics are brought in, such as, digital simulation, jewelry design with the theme of architecture, etc. Through the competitions, students can broaden their horizons, emancipate their minds and improve their innovation abilities of design.

\section{The Reform of Teaching Methods}

In the past, the backward teaching conception and the obsolete teaching methods have contributed significantly to a lowly efficient education. Teachers have been talking about the essential knowledge from their point of view in the classroom, which occupies the time and space for students to study spontaneously, think independently and explore actively. At the same time, careful explanation and repetition by teachers develops a strong sense of dependence in the students. They receive knowledge passively in this process, and have been deprived the rights and enthusiasm of self-perception, self-experience and self-internalization. It would lead to their knowledge structure cannot be integrated, the skills and abilities are difficultly internalized. If we continue to use this method, it is impossible to cultivate innovation and practice abilities in the students. So we have made some reformations on the traditional teaching methods of architectural design.

\subsection{Flipped Classroom}

The previous teaching mode, "theory teaching—cognition analysis—-design research", has been changed to meet the new training objectives. Students need to experience and recognize the real places where they will do design before their class learning. After that they might get to the classroom with questions. In addition to the teaching of basic theory and skills, discussion and analysis are the main contents in class. Teachers instruct students the methods of solving problems instead of helping them to solve problems. Students can choose their interested subject topics to continue, which would mobilize their initiative greatly. Teachers can also get acquainted with the characteristics of each student easily through the class discussion, and teach students in accordance of their aptitude. Finally, the new mode, "experience-cognition-discussion-research-design-evaluation", is formed (i.e., Figure 2). Students occupy the initiative position in the main teaching \& learning sections, and teachers' instruction is more targeted.

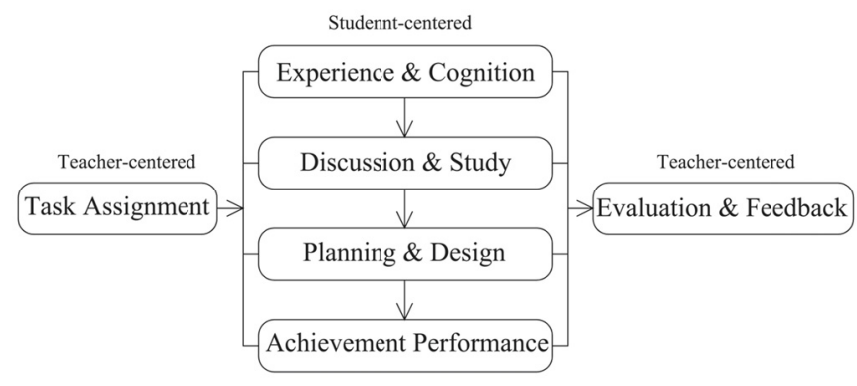

Figure 2. The new teaching mode

\subsection{Break up The Whole into Parts}

Architectural design is a complex process with both perceptual creation and rational thinking. The ability of architectural design is a comprehensive capability based on massive theories and practices, which need us to accumulate experience for a long time. The junior students who just entered the university immediately begin to 
do design, usually attend to one thing but lose sight of others. For instance, paying attention to the function but ignoring the form; paying attention to the form but also ignoring the spatial structure, materials and the surrounding environment, etc. The comprehensive capability required by architectural design includes the abilities of problem analysis, space imagination, design performance, innovation \& practice, teamwork and so on (i.e., Table 1). The decomposed trainings in different courses and assignments which have been done before a composite design of small buildings can achieve better results. This is the method "breaking up the whole into parts, and conquering one by one".

Table 1. Abilities and trainings for architectural design and research

\begin{tabular}{cll}
\hline & Items & Setting Trainings \\
\cline { 2 - 3 } & Learning \& analysis & Works analysis, discussion in class \\
Design \& & Spatial imagination & Spatial cognition training, works appreciation \\
Research & Design performance & Art Sketch, model making \\
Ability & Practice & Construction experiment, building surveying and mapping \\
& Innovation & Design competition, freshman seminar \\
& Teamwork & Construction experiment \\
& Criticism & Public commentary of drawings \\
\hline
\end{tabular}

In the teaching process, the concepts of culture, region, energy, history and values should be added to each stage. We need to improve students' attention to society and direct them to reach a higher position to see a wider area. The students would assimilate into society in a global perspective, and treat every design task seriously with multidimensional mode of thinking. Reforming the cultural method of design ability in architecture, will help students to do better in multiple cognition, cooperation and innovation, then they gradually give priority to the discussion of social problems.

\subsection{Technical Assistance}

Micro Learning Resource System has been set up by means of information technology. It provides a great number of videos in which knowledge and principle are taken as the main content in accordance with the structure of curriculum system for students to learn online. In this way, students could learn difficulties and priorities repeatedly on the basis of their own situation. And because of the preliminary study of the basic theory on the extracurricular, we have more time to develop skills and discuss problems in class. The students can also get more extended materials and receive assignments and feedbacks from the Micro Learning Resource System. Moreover, we are going to build a virtual laboratory for building structures, where students can use VR technology into a variety of building models in the future. The virtual laboratory will help them experience the inner space and observe the construction of the building nodes. Undoubtedly, it would greatly improve the efficiency of teaching.

\section{Conclusion}

Chinese society is facing the significant transformation with the rapid development of economy. The construction field will transition to the era of reconstruction and green renewal for existing buildings from the era of large-scale demolition and construction in the past. We do not lack of traditional architectural designers, but need a great deal of innovative design talents and practical engineering talents for the future. Therefore, architectural education must make corresponding changes starting from the junior professional courses, no longer just emphasizes the teaching of basic theoretical knowledge and skills. Instead, the original curriculum system in the training program would be adjusted to strengthen the cultivation of students' practice ability and innovation ability. The previous method, instruction in class by teacher and passive reception by students, cannot be used. The innovative design thinking of students is inspired through active experience, discussion and practice, the comprehensive quality of students is improved through decomposed trainings, and the professional vision is widened through supplementary frontier theory, all these attempts could better adapt to the development of the future society.

\section{References}

Chen, X., Zhou Z., \& Zhu, Y. (2015). Development and enlightenment of research-oriented design teaching in architectural education. Architecture and culture, 11(8), 146-147.

Huang, J. (2016). Research and Exploration on the teaching of basic courses in the first year of Architecture. 
Western Quality Education, 2(3), 70.

Jiang, Y., \& Bao, J. (2009). Comparative study on design/build courses. World Architecture, 29(3), 132-137.

Jiang, Y., Ke, R., Song, Y., \& Wang, L. (2011). From design to construction: design/construction studio at Tsinghua University. New Architecture, 28(4), 18-21.

Li, Z. (2016). Architectural education: upgrading by changing. Architectural Creation, 27(4), 140-147.

Liu, W., \& Li, W. (2014). Between change and dialectical, teaching characteristics about the first grade of basic architecture design course in independent colleges. Art and Design, 11(9), 155-157.

Ministry of Education. (2011, February 11). Some opinions on the implementation of the education program of outstanding engineers. China Education Daily (p. A1).

Peng, L, \& Jia, D. (2016). Teaching innovation of the first grade design course based on construction experience: wood-made teaching of preliminary architecture course. Huazhong Architecture, 33(7), 173-178.

Song, Y., Ding, J., Zhu, N., Jiang, Y., \& Zhang, H. (2015). Optimization of teaching method on experience construction studio for the $1^{\text {st }}$ grade undergraduate students. China Architectural Education, 7(2), 5-11.

Wang, C. \& Yang, M. (2016). Exploration on the reform of preliminary experimental course in architecture. Modern Agricultural Science and Technology, 45(21), 285-286.

Wang, Z., \& Sun, Y. (2010). Designing with experiments - the teaching exploration of architectural design integrated with construction. New Architecture, 27(3), 118-121.

Wu, F., Cao, B., \& Yang, J. (2017). Exploration on the reform of the practice teaching of architectural design course for the second grade students. Journal of Liaoning University of Technology (Social Science Edition), 19(2), 68-71.

Zhang, N., Xiong, Y., Jin, Y., \& Zhao, J. (2016). The new teaching model of the preliminary course of architecture: "task driven" flipped classroom-taking architectural expression skill as an example. Western Quality Education, 2(11), 146-147.

Zhong, D., \& Tu, S. (2005). The new development in the new period: Rethinking of architectural education in China. Architectural Journal, 49(12), 20-23.

Zhong, G., \& Song, G. (2011). Reconstruction the classics: research on teaching practice of digital tectonic in SCUT. New Architecture, 28(4), 42-45.

\section{Copyrights}

Copyright for this article is retained by the author(s), with first publication rights granted to the journal.

This is an open-access article distributed under the terms and conditions of the Creative Commons Attribution license (http://creativecommons.org/licenses/by/4.0/). 